\title{
Analysis of the Failure of Hierarchy Function of Branch in Loan Management System of China's Commercial Bank and Its Countermeasures
}

\author{
Liguo $\mathrm{He}$ \\ School of Economics \\ Sichuan University \\ Chengdu, China
}

\begin{abstract}
In January 2018, the case of a branch's illegal credit granting broke out, which is expected to cause huge losses of nearly 10 billion yuan. This paper studies the reasons why this case breaks out? This paper starts with the loan management system of the "head office-branch-subbranch" of China's commercial banks, uses the principal-agent theory to analyze the reasons why the branches fail to control the risks, and proposes countermeasures in a targeted manner.
\end{abstract}

Keywords—branch; loan management; principal-agent; risk

\section{INTRODUCTION}

Like the enterprises in other industries, banks are also enterprises. They are special in the credit business they carry out. The credit business brings a lot of profits to the banks and also causes great losses to the banks. To this end, banks emphasize the control of credit risk rather than enterprises in other industries. The loan management system of "head office-branch - sub-branch" is one of the main means of controlling risks.

On January 19, 2018, the official website of the former China Banking Regulatory Commission released a message. In order to cover up the non-performing loans, a branch has granted 77.5 billion yuan to 1,493 shell enterprises through various means. The relevant enterprises bear the nonperforming loans, and the final loss is estimated to be 10 billion yuan. This case shows that in the current loan management system of commercial banks in China, once the branch cannot play the role of controlling risk, it will have devastating impact.

\section{LOAN MANAGEMENT SYSTEM OF CHINA'S COMMERCIAL BANKS}

Most of China's commercial banks adopt the loan management system of "head office-branch - sub-branch". The head office is responsible for the construction of the loan management system, the construction of the credit information system, the formulation of credit policies, the investigation and review of report templates, and the authorization of branches. Also, it reviews credit operations beyond branch authority, checks the credit business of each branch, and plays the role of "guidance" and "supervision".
The branch is responsible for the formulation of credit policies in the region, the management of credit officers, the examination and approval of credit business, the pricing management of credit business, lending and post-loan management, and plays the "control" role. There are subbranches in the branch system (specific development and maintenance of credit companies), corporate banking departments (lead marketing of credit companies), risk management departments (specific review of credit business, lead approval), planning and finance departments (pricing management of credit business), post-loan management departments and compliance supervision departments (compliance inspection on business and personnel). With professional division of labor, mutual checks and balances, they jointly build a fully functional, scientific and reasonable credit business system.

The sub-branch is responsible for the marketing of credit companies, writing investigation reports, providing supplementary information for the review and approval of the general branches, issuing loans, post-loan management (continuous tracking of business operations and risks), and collecting the principal and interest of loans. It plays the role of "execution".

The loan structure of "head office-branch-sub-branch" is the best choice under the realistic conditions of China's vast territory and large population. Establishing branches in each province and granting certain approval authority to branches can improve the efficiency of credit decisionmaking and shorten the decision-making cycle, and improve corporate satisfaction. And then, the banks can establish cooperation with high-quality enterprises in the fierce market competition (non-quality enterprises are also easy to hitchhike). On the other hand, there are certain differences in the economic development level and industrial structure of the provinces. It is impossible for the head office to adopt non-discriminatory credit policy for each branch. To a certain extent, the head offices allow the branches to focus on developing credit business in the region, which can improve the regional adaptability of credit business, and facilitate the local development of credit business. 


\section{MULTIPLE PRINCIPAL-AGENT RELATIONSHIP IN THE LOAN MANAGEMENT SYSTEM OF CHINA'S COMMERCIAL BANKS}

The loan management system of "head office - branchsub-branch" is a multi-agent relationship (Jiang Jianqing, 2001). In the principal-agent relationship of "head officebranch", the head office is the principal and the branch is the agent. In the principal-agent relationship of "branch-subbranch", the branch is the principal and the sub-branch is the agent. Multiple principal-agent relationships may lead to the strengthening of business direction, the amplification of corporate preferences, the weakening of risk control capabilities, and the increase of potential risks.

\section{A. Analysis on Principal-agent Relationship Between "Head Office and Branch"}

In the principal-agent relationship of the "head officebranch", the head office evaluates the branches under the jurisdiction by setting key tasks such as loan volume, loan profit, and non-performing rate, and grants different approval rights to each branch (for credit business within the authority, the approval of the branch is approved, and it will take effect without being submitted to the head office for approval). And the head office allocates corresponding salary, bonus, honor and other resources according to the assessment results.

For the head office and the branch, the focus of the game between the two parties is the approval authority. For the head office, releasing more approval authority to the branch means accepting greater uncertainty, and they may bear greater potential losses in the future. Therefore, the head office tends to reduce the approval authority granted to each branch. For the branches, striving for greater approval authority means increased credit flexibility, reduced overall business difficulty, better assessment results, and more resources. In order to maximize their own income (salary, bonus, honor), the branches are willing to expand their approval authority.

As an agent, the branch has information advantages. The head office does not have accurate and timely information on the direction of the branch's credit business, the real situation of the enterprise, and the review and approval. The head office cannot observe the degree of effort and compliance of the branch in specific credit behaviors. The award is based on the results of the business (the completion of the task indicators). In order to complete the performance indicators issued by the head office, and increase its own revenue, the branches carry out short-sighted but quick-acting credit behaviors, such as selecting an easy-to-follow credit business direction, increasing the rate of sub-accounts (the probability of approval of credit business), increasing the credit line for individual enterprises, etc. And this would form tendentiousness guidance for the industry, the nature of the enterprise, and the scale of the enterprise. However, the branch is a complex system composed of multiple departments with checks and balances. The adjustment of credit behavior requires the cooperation of relevant departments, and it is subject to inspection by the head office and external regulatory agencies. The participating departments must bear corresponding dereliction of duty or even illegal liability, and the cost is too high. This system design constitutes the constraint on the credit behavior of branches.

\section{B. Analysis on Principal-agent Relationship Between "Branch and Sub-branch"}

In the principal-agent relationship between "branch and sub-branch", the branch is the background of the credit business, and the sub-branch is the front line of the credit business. The branch decomposes the task indicators of the head office to each sub-branch, which is completed by the sub-branch. The branch will assess the sub-branches according key task indicators such as loan volume, loan profit, and non-performing rate. And the branch allocates corresponding bonuses, honors and other resources.

In the principal-agent relationship between the branch and the sub-branch, the focus of the game between the two parties is the risk of each credit business, that is, the default rate of the enterprise. And the result of the game is the rate of passing initial application. As an agent, the branch knows the true situation of each credit business and has information advantage. In order to reduce the risk of credit business, the branch needs to make more efforts to collect enterprise information. It is difficult for branches to directly judge the degree of effort and compliance of the sub-branch. The credit business information finally presented by the sub-branch can be observed. And the review and approval of the sub-branch can be carried out according to the established credit policy. More efforts of the sub-branch may not bring the same proportional increase in the rate of passing initial application. By adjusting the rate of passing initial application in different industries, different companies, and different companies, the branches can have greater impact on the level of effort and compliance of sub-branches. It is a rational choice to reduce the difficulty of work, increase its own income (salary, bonus, honor), and choose a company with a high passing rate (industry and enterprise supported by the credit policy of the branches).

Under the mechanism of compulsory guidance of branches, the freedom of sub-branches to choose enterprises is low. It is usually based on the preference of the branch to conduct credit business marketing. It is not willing to carry out the credit business with low rate, even if the risk of certain business is small and the income is relatively low. Thus, the industry, the nature of the enterprise, and the scale of the enterprise are formed. For example, sub-branches favor the credit business for large enterprises. And the willingness to have credit business with small and micro enterprises is low. The branches recognize that large enterprises have strong anti-risk ability and small and micro enterprises have weak anti-risk ability. Through the credit business review and approval process, the information is passed to the sub-branch and continuously strengthened, which further causes the credit resources to be concentrated in large enterprises. And the financing difficulty of small and micro enterprises is further increased. 
As an agent, in order to increase the income, the subbranch has the motive to issue loans in violation of regulations in addition to selecting a company with a high rate of passing initial application. Through the screening and combination of information and even fraud, the sub-branches pass information beneficial to the enterprises, and guide the branch to improve the passing rate of single credit business. However, in the context of constant internal regulation of banks and stricter inspections, this moral hazard faces greater risks and penalties, and inhibits the violations of subbranches.

\section{ANALYSIS ON THE FAILURE OF BRANCH-LEVEL LOAN RISK CONTROL}

In the loan management system of commercial banks, branch is the connecting link between the preceding and the following. On the one hand, as an agent, the branch accepts the authorization of the head office, implements the credit policy of the head office, and cooperates with the head office to check the credit business. On the other hand, as the client, the branch completes the establishment and staffing of the regional credit business, formulates credit policies, organizes credit business marketing, and carries out the review and approval of credit business and post-loan inspection. Within the scope of the authorization of the head office, the branch can conduct credit business more independently with complete institutional setup.

As agents, branches and sub-branches may have moral hazard (Jiang Jianqing, 2001). That is to use information advantages. Starting from the interests of branches and subbranches, they pursue the maximization of their own utility. In extreme cases, branches and sub-branches may even take risks and violate the rules and regulations to carry out credit business. Although this method can quickly improve the performance of branches and sub-branches in a short period of time, it will inevitably bring greater risks in the long run.

\section{A. Analysis on the Impact of Current Performance \\ Evaluation Mechanism on Credit Business Direction}

Under the current performance evaluation mechanism of commercial banks, the way in which the head office issues various credit indicators to branches is mostly based on the cardinal number multiplied by a certain planned completion rate. Most of these completion rate indicators are higher than the growth rate of GDP during the same period. There are many banks and employees. And the competition in the banking industry is becoming more and fiercer. The difficulty in completing the task indicators is increasing.

Looking at this cardinal number, it is usually the performance data at the end of last year. According to the ratchet effect, the better the performance at the end of last year is, the greater the absolute value of the task gap in that year is, and the greater the task pressure is. Under the ratchet effect, performance indicators continue to be accumulated, and branches can only continue to make the increase in the base of the previous year. How was the base of the previous year formed? After the branch selects the direction of credit business and corporate preference, it achieves better results in the short term and maximizes its own interests. The branch will continue to strengthen this direction and preference in the future, which becomes the cumulative base. The longer the time is, the bigger the scale of this base will be. Correspondingly, once the direction of credit and corporate preferences change, the magnitude of the decline in performance may be greater. The branch tries to avoid this, especially during the term of the same branch president. As a result, the original credit direction and corporate preferences have become path dependence that is difficult to change, making credit risk be snowballs.

In the violation case of a branch, the branch president has served for a long period of 15 years since 2002. During his tenure, he focused on the development of hydropower, steel, coal and other industries. He achieved excellent results in the initial stage, and the scale and per capita profit of the branches increased continuously. Leading the local jointstock banks, it is the typical bank for study. The branch president has won huge honor, and the cadres and employees have earned much higher salary than the market average salary. The adjustment of credit business direction achieved good performance in the early stage. Good performance brought honor and high income. Honor and high income promoted the branch to strengthen business direction, and pursue better performance. It keeps on the circulating. For sunrise industry, the customer quality is good, and the potential risk is small. There is no bad burden. This ratchet effect will form positive incentive. For the sunset industry, the customer quality is poor, and the potential risk is large. The bad burden is heavier. The ratchet effect creates negative incentives, leading the banks go further on the wrong path. In the context of constantly strengthening credit restrictions on steel, coal and other industries, and even compressing the amount of loans, the branch's behavior against the trend has gained a lot of money in the short term. However, it has laid huge business risk. Later, the steel and coal industries are not good. The non-performing loans of the branch increase. Through the debt-based purchase, the bank loan to the shell companies. The shell companies make the repayment for the non-performing loan companies, which can repay capital with interest. It is to use the time to exchange the space. The banks hope to help companies to survive the low ebb. And then, the banks can maintain good performance and "zero badness".

\section{B. Analysis on the Impact of Strengthening Executive Force on Credit Business Compliance}

Within the scope of authorization of the head office, the branch selects the direction of the credit business that is focused on development according to the policies of the head office. And the branch selects the corresponding scope of the enterprises. In this process, in order to cope with fierce market competition, and complete heavier mission indicators, it is necessary to improve the execution of branches and improve the efficiency of decision-making. The strengthening of executive power will increase the authority of leadership. It emphasizes the connection of vertical power chain. The subordinate obey the superior. This has weakened the horizontal balance mechanism (Sun Bocan, Song Anping, 
Ma Qingguo, 2003). The branch president is given greater rights. In terms of personnel appointments and credit business directions, the branch president has more rights. The longer the branch president is in the same region, the greater the influence on the appointment and business direction of the employees in the jurisdiction will be.

The branch has complete post settings such as credit business initiation, risk review, loan issuance, and post-loan management. From the point of view of the branch, these positions are supervised by each other. Their respective job responsibilities and work objectives are quite different. However, from the point of view of the branch, the appointment of these positions mainly depends on the opinions of the leaders of the branches. After the personnel are employed, it is the best choice to please the leader and even obtain good feeling of the leader. Based on this, the objectives of each position have certain convergence.

With the psychological tacit understanding of each position, the direction of credit business determined by the branch president can be implemented and strengthened through the specific implementation of each position. The branch must follow the business direction to improve the rate of passing initial application. The social and economic structure changes, the industries that the branch credit business is biased face adjustments. The business direction that has brought greater profits will result in huge nonperforming loans. In the face of task indicators and market competition, the business direction is changed. It means sharp decline in the base, a doubling of the task gap, and sharp rise in non-performing loans. The branches will plummet in the assessment of the head office, and the ratio of various resources will greatly reduce. During the term of the same branch president, he tried to avoid this kind of cliffstyle assessment results. Therefore, if this happens, the branch president initiatively violates regulations, maintains business development, and conceals non-performing loans. This is one of the branch' choices. In this extreme case, the risk control system will be seriously ineffective. And credit service initiation, risk review, loan issuance, post-loan management and other positions will become the assembly line with the violation use of professional knowledge in the approval authority of the branch.

In the case of branch violation, the original branch president and the two former deputy governors were downgraded or recorded respectively, and 195 middle-level and below responsible persons were internally accountable (formerly the China Banking Regulatory Commission website, 2018) ). The branch president has served for 15 years and has great influence on the appointment of personnel in various positions. With continuous adjustment, the psychological tacit understanding of the business concept of corresponding business personnel may increase. Thus, they participate in a large number of illegal businesses to varying degrees. The branch fabricated false uses, split up credit granting, exceeded the authority of approval and other means, and transacted credit, inter-bank, financial management, letters of credit and factoring in violation of regulations, granting 77.5 billion yuan to 1,493 shell enterprises (formerly the China Banking Regulatory
Commission website, 2018). The average credit line of each company is 51,908,900 yuan, making full use of the approval authority of the head office to the branch (Zhang Yan, Song Jie, 2018). There are many enterprises involved in illegally handling credit business. The business is large, which is out of the scope of branch business. Therefore, the number of people involved in the case was numerous. And it was identified as an organized fraud case led by a branch by the Banking Supervision (formerly the China Banking Regulatory Commission website, 2018).

\section{Analysis on the Amplification Effect of the Branch's Active Violations on Credit Risk}

According to the transformer theory proposed by Professor Zhang Weiying, under the multi-level principalagent relationship, there are multiple principal-agent relationships from the initial principal to the final agent. This relationship is similar to multi-level transformers, and each transformer can be seen as a step-down transformer. The more the number of stages is, the greater the magnitude of the step-down transformer will be (Cen $\mathrm{Ke}, \mathrm{Fu}$ Xiaoyong, Deng Xinhua, 2015). For the credit management structure of "head office-branch — sub-branch", the branch controls the review of credit business and focuses on risk control. The branch controls the finalist of credit companies and focuses on business development. If the branch weakens the risk control, there will have a large number of risky enterprises in the finalist of the sub-branch, and the credit risk will increase greatly. If the branch also focuses on business development, there will have a large amount of fraud high-risk enterprises in the finalist of the sub-branch. Credit risk enlarged in multiples. It has caused devastating effects and magnified damage to superiors (head office). In the case of the branch's violation, it ultimately caused an estimated loss of 10 billion yuan. The loss was huge, far greater than the losses caused by the violation of a single branch. (Formerly China Banking Regulatory Commission website, 2018)

\section{CONCLUSION}

If the branch fails to play its due role in the credit business management system, it will amplify the credit risk of the bank and cause huge non-performing loans. Therefore, strengthening the constraints on branches and regulating the credit business of branches is of great significance to the healthy development of banks.

\section{A. To Strengthen the Credit Business Direction of the Head Office}

The head office formulates an overall credit policy according to the national economic development. For industries with high risks such as compression and withdrawal, the total amount of credit should be strictly controlled, and branches are not allowed to break the upper limit. For key industries in the region, branches are allowed to have the focus. However, the branch should control the total amount. The credit ratio of the industry is controlled within a reasonable range. 


\section{B. According to the Actual Controller's Credit, the Credit Can't Be Split}

For each credit business, it is necessary to find out the final actual controller, include all the enterprises under the same actual controller into the group credit, and control the total credit of the group to avoid the branch to split up the credit and reduce the business risk.

\section{To Rotate Important Leaders Regularly}

For leaders such as branch presidents and risk directors who have significant influence on credit business, the banks conduct regular cross-regional rotations to avoid excessive long-term employment, which will have an adverse impact on the credit business direction, related post personnel, and credit business approval process.

\section{To Strengthen Daily Inspection of Credit Business}

From time to time, the branch's credit business is subject to a high proportion of random checks or audits, checking whether the branch invests in high-risk and high-return fields, whether it is over-lending, whether the loan is concentrated, whether the collateral is effective. Also, the bank should check the loan contract, credit conditions, funds payment and other links to enhance business compliance.

\section{E. To Use Big Data to Analyze Abnormal Conditions}

Commercial banks have branches in various parts of the country. The head office understands the credit amount, industry distribution, non-performing rate, enterprise size, interest rate and other information of each branch. It can find the abnormal data of a branch through horizontal comparison. And then, the head office can analyze the data, find the reasons behind, and eliminate risks in a timely manner.

\section{REFERENCES}

[1] Formerly China Banking Regulatory Commission, http://www.cbrc.gov.cn/chinese/home/docView/0178BB8828CD411 3BB61BBCA39B7385B.html, January 19, 2018.

[2] Jiang Jianqing. Research on the management of branches of stateowned commercial banks, Financial Research, No. 9, 2001, P6.

[3] Sun Bocan, Song Anping, Ma Qingguo. Research on credit decision of loan review committee of commercial bank and its performance evaluation, Financial Research, No. 4, 2003, P99.

[4] Zhang Yan, Song Jie. "Zero badness" is shattered, "China Economic Weekly", January 28, 2018.

[5] Cen Ke, Fu Xiaoyong, Deng Xinhua. "Zhang Weiying's Fable Economics", Shanghai People's Publishing House, August 2015, P187. 